\title{
A NEW LINKAGE IN THE HOUSE MOUSE : UNDULATED AND AGOUTI
}

\author{
T. C. CARTER \\ Department of Genetics, University of Cambridge
}

Received 21.vi.47

\section{INTRODUCTION}

WRIGHT (1947) has reported the occurrence of a new hereditary character in the house mouse (Mus musculus, L.) ; the affected mouse typically shows soft undulations of the tail and a tendency to a hunchback. She concluded that the inheritance of the character is unifactorial and recessive, and suggested the name "undulated" and the symbol un for the mutant gene concerned.

The present paper gives data which indicate that un is closely linked to the agouti locus ; it therefore belongs to Linkage Group V (Dunn, Grüneberg and Snell, 1940). No data are yet available on its segregations with the other mutants in this group, namely pallid (Roberts and Quisenberry, 1935), wellhaarig and kreisler (Hertwig, I942), nor with hydrocephalus-I (Glark, I936).

\section{MATERIAL}

The greater part of the material to which the data refer consists of four lines which are being set up in the Department of Genetics, Cambridge University. With a view to an extensive test of possible linkages of the new factor, undulated was introduced into these lines by Miss Margaret Wright during 1944 and 1945. It was intended to test it in a fifth line with a representative of Linkage Group V, namely wellhaarig; but this was delayed as wellhaarig was not then available outside Germany. Meanwhile the other four lines, which were not intended to segregate at the agouti locus, continued to do so ; and during 1946 it became obvious that this continued segregation of the agouti alleles was associated with the segregation of undulated.

The fact that the greater part of the data arose in this way explains why most of the matings concerned were intercrosses rather than backcrosses; however, the linkage proved to be close, and the coupling intercrosses (which constitute the greater part of the data) are therefore almost as informative as coupling backcrosses.

Four of the agouti alleles were involved, namely $\tan \left(a^{t}\right)$, lightbellied agouti $\left(A^{w}\right)$ and non-agouti $(a)$ as well as agouti itself $(A)$. Tan was acting as a dominant (to non-agouti) in the repulsion matings and as a recessive (to light-bellied agouti or to agouti) in the coupling matings. 
All the mice were normally classified as early as possible, but the classifications were checked when the animals were between 18 and 2I days old.

\section{DATA}

The basic data are given in table I. This shows the number of progeny in each of the phenotypic classes from matings of five types :

Coupling intercrosses with agouti $A U n / a^{t} u n$ i $\times A U n / a^{t} u n \delta^{t}$ segregating

Coupling intercrosses with light-bellied $A^{w} U n / a^{t} u n$ 우 $\times A^{w} U n / a^{t} u n \sigma^{*}$ agouti

Coupling backcrosses with segregation in $A^{w} U n / a^{t} u n$ 우 $\times a^{t} u n / a^{t} u n \delta^{t}$ the female

Coupling backcrosses with segregation in $a^{t} u n / a^{t} u n+q \times A^{w} U n / a^{t} u n \delta^{*}$ the male

Repulsion intercrosses . . . . $a U n / a^{t} u n+\$ \times a U n / a^{t} u n \delta^{\hat{0}}$

In one of these bodies of data, namely the coupling intercrosses in which agouti and tan were segregating, a more complete classification is possible, by virtue of the incomplete dominance of agouti over $\tan$; details of this classification are not, however, given.

The data are unselected, save in the following respects :-

(i) Any animal which died before reaching the age of 14 days has been excluded. It was found that some animals which appeared at birth to have undulated tails later became fully normal ; acceptance of an unchecked early classification might therefore have led to biassed results. The age of I4 days was chosen because this was considered to be the earliest age at which a sure distinction could be made between undulated and normal animals.

(ii) Albinism was segregating in one of the lines : albinos, which could not be classified for the agouti phenotype, were excluded.

(iii) Fused was segregating in a few matings in one line. While there was no difficulty in classifying the fused progeny as such, difficulty was encountered in deciding whether these mice were also undulated or not; they were therefore excluded.

\section{ANALYSIS OF THE DATA}

On inspection, the data give an impression of good unifactorial segregations of both of the loci concerned (undulated and agouti), but of close linkage between them. This impression is confirmed by statistical analysis, an outline of which is given in table 2 :-

(i) Segregation at the undulated locus. All five bodies of data show good unifactorial segregation at this locus. 
(ii) Segregation at the agouti locus. The agreement between observation and expectation for the segregation at this locus is extremely good. As the data were unselected, except as indicated above, this must be attributed to chance.

TABLE I

\begin{tabular}{|c|c|c|c|c|c|}
\hline \multirow{2}{*}{ Mating type } & \multirow{2}{*}{ Mating no. } & \multicolumn{4}{|c|}{ Phenotypes of progeny } \\
\hline & & $A U n$ & A un & $a^{t} U n$ & $a^{t} u n$ \\
\hline \multirow[t]{3}{*}{ Coupling intercross . } & $\begin{array}{l}V / 24 \\
V / 25 \\
V / 28 \\
V / 29 \\
V / 3^{\circ}\end{array}$ & $\begin{array}{r}2 \\
14 \\
6 \\
4 \\
6\end{array}$ & $\begin{array}{r}\cdots \\
\text { I } \\
\cdots \\
\cdots \\
\cdots\end{array}$ & $\begin{array}{l}\ldots \\
\ldots \\
\cdots \\
\cdots \\
\cdots\end{array}$ & $\begin{array}{l}3 \\
2 \\
2 \\
2 \\
4\end{array}$ \\
\hline & Totals & 32 & I & $\cdots$ & 13 \\
\hline & & $A^{w} U_{n}$ & $A^{w} u n$ & $a^{t} U_{n}$ & $a^{t} u n$ \\
\hline \multirow[t]{2}{*}{ Coupling intercross . } & $\begin{array}{r}* 6 / 17 \\
* 6 / 18 \\
6 / 30 \\
6 / 51 \\
* 8 / 13 \\
* 8 / 15 \\
* 8 / 16 \\
8 / 34\end{array}$ & $\begin{array}{r}12 \\
4 \\
36 \\
40 \\
32 \\
35 \\
3 \\
17\end{array}$ & $\begin{array}{r}\ldots \\
\cdots \\
\cdots \\
I \\
I \\
2 \\
\cdots \\
\cdots\end{array}$ & $\begin{array}{r}\cdots \\
\cdots \\
2 \\
\cdots \\
1 \\
1 \\
\cdots \\
\cdots\end{array}$ & $\begin{array}{r}4 \\
1 \\
13 \\
7 \\
12 \\
10 \\
\cdots \\
9\end{array}$ \\
\hline & Totals & 179 & 4 & 4 & 56 \\
\hline \multirow[t]{2}{*}{$\begin{array}{l}\text { Coupling backcross ; } \\
\text { female segregation }\end{array}$} & $\begin{array}{l}6 / 4^{8} \\
6 / 5^{6} \\
8 / 4^{2}\end{array}$ & $\begin{array}{l}5 \\
7 \\
1\end{array}$ & $\begin{array}{l}\cdots \\
\cdots \\
\cdots\end{array}$ & $\begin{array}{r}\cdots \\
2 \\
\cdots\end{array}$ & $\begin{array}{l}2 \\
8 \\
1\end{array}$ \\
\hline & Totals & I 3 & $\cdots$ & 2 & I I \\
\hline \multirow[t]{2}{*}{$\begin{array}{l}\text { Coupling backcross ; } \\
\text { male segregation }\end{array}$} & $\begin{array}{r}6 / 53 \\
8 / 37 \\
\mathrm{VII} / 29 \\
\mathrm{VII} / 30\end{array}$ & $\begin{array}{r}7 \\
9 \\
\cdots \\
7\end{array}$ & $\begin{array}{r}\cdots \\
\cdots \\
\cdots\end{array}$ & $\begin{array}{r}\cdots \\
1 \\
\cdots\end{array}$ & $\begin{array}{r}1 \text { I } \\
8 \\
\text { I } \\
\text { I }\end{array}$ \\
\hline & Totals & 23 & I & 2 & 21 \\
\hline \multirow[t]{3}{*}{ Repulsion intercross } & & $a^{t} U n$ & $a^{t} u n$ & $a U n$ & a un \\
\hline & $\begin{array}{r}* 2 / 10 \\
{ }^{*} 2 / 16 \\
2 / 23 \\
2 / 24 \\
{ }^{2} 21 / 8 \\
21 / 21 \\
21 / 27 \\
V / 18\end{array}$ & $\begin{array}{r}6 \\
13 \\
7 \\
18 \\
21 \\
15 \\
20 \\
7\end{array}$ & $\begin{array}{r}4 \\
7 \\
7 \\
9 \\
11 \\
15 \\
6 \\
2\end{array}$ & $\begin{array}{r}4 \\
4 \\
3 \\
11 \\
10 \\
4 \\
13 \\
4\end{array}$ & $\begin{array}{l}\cdots \\
\cdots \\
\cdots \\
\cdots \\
\cdots \\
\cdots \\
\cdots \\
\cdots\end{array}$ \\
\hline & Totals & 107 & 61 & 53 & $\cdots$ \\
\hline
\end{tabular}

The data given by Wright (1947) include details of some or all of the progeny of the matings here marked with an asterisk.

(iii) Method of analysis of the linkage. The "scoring method" developed by Fisher (1946), which is a variant of his 
"maximum likelihood" technique, has been adopted; its advantages include the comparative ease with which a joint test of significance and a joint estimate of the recombination fraction are obtainable from the five bodies of data.

(iv) Significance. The $\chi^{2}$ testing independence of segregation, which has one degree of freedom, is

$$
\chi^{2}=288 \cdot 7 \text {. }
$$

The corresponding probability is extremely small; a hypothesis of independent segregation is therefore untenable.

(v) Intensity of linkage. The joint estimate obtained for the recombination fraction is

$$
p=3.86 \text { per cent. }
$$

and its standard error is calculated to be

$$
s=\mathrm{I} \cdot 02 \text { per cent. ; }
$$

but Stevens (1942) has pointed out that it is incorrect to use a standard error to find fiducial limits in cases such as this where $p$ is small compared with unity. The present results are not in a form suitable for the direct application of the correction tables he gives, and so the " equivalent backcross data" have been calculated; i.e. a calculation has been made of the numbers of recombinant and nonrecombinant progeny, which, if they had all been produced by backcross matings, would have yielded the same total score and the same total amount of information. Stevens's corrections have been applied to these figures, and the limits within which $p$ probably lies (for a 5 per cent. significance level) are found to be

$2 \cdot 12$ per cent. and $6 \cdot 4^{2}$ per cent.

(vi) Homogeneity of the data. For the purpose of obtaining a joint estimate of the recombination fraction, it has been assumed that the frequency of crossing-over in the male is the same as that in the female, and also that it is the same when $A^{w}$ or $a$ segregates with $a^{t}$ as when $A$ segregates with $a^{t}$. These assumptions are not contradicted by the data; the heterogeneity $\chi^{2}$ is not more than 2.523 , which corresponds with a probability exceeding 0.5 since it has four degrees of freedom. The contributions to this $\chi^{2}$ made by the backcross data alone amount to $\mathrm{r} \cdot 835$, which for one degree of freedom corresponds with a probability exceeding $0 \cdot 17$; and the contributions made by the coupling intercrosses amount to 0.589 , which for one degree of freedom corresponds with a probability exceeding $0 \cdot 3$. 
TABLE 2

Segregation at the undulated locus : Recessives observed $\chi^{2}$." expected.

Segregation at the agouti locus : Recessives observed $\chi^{2}$." expected

Linkage : Testing independence $(p=0.5)$ $\Sigma_{\frac{m}{m}}^{a} \frac{d m}{d p}$ (score) $n \sum \frac{\mathrm{I}}{m}\left(\frac{d m}{d p}\right)^{2}$ (information).

Total score

Total information

Independence : $\chi^{2}$

\begin{tabular}{|c|c|c|c|c|}
\hline $\begin{array}{c}\text { Coupling } \\
\text { intercrosses } \\
A \text { and } a^{t}\end{array}$ & $\begin{array}{c}\text { Coupling } \\
\text { intercrosses } \\
A^{w} \text { and } a^{t}\end{array}$ & $\begin{array}{c}\text { Coupling } \\
\text { backcrosses: } \\
\text { male } \\
\text { segregating }\end{array}$ & $\begin{array}{l}\text { Coupling } \\
\text { backcrosses: } \\
\text { female } \\
\text { segregating }\end{array}$ & $\begin{array}{l}\text { Repulsion } \\
\text { intercrosses }\end{array}$ \\
\hline $\begin{array}{l}14 \\
11 \cdot 50 \\
0 \cdot 725\end{array}$ & $\begin{array}{l}60 \\
60 \cdot 75 \\
0 \cdot 009\end{array}$ & $\begin{array}{l}22 \\
23 \cdot 50 \\
0.479\end{array}$ & $\begin{array}{l}\text { II } \\
\text { I } 3 \cdot 00 \\
0 \cdot 154\end{array}$ & $\begin{array}{l}6 \mathrm{I} \\
55^{\cdot 25} \\
0 \cdot 798\end{array}$ \\
\hline $\begin{array}{l}\text { I } 3 \\
\text { I I } 50 \\
0 \cdot 26 \text { I }\end{array}$ & $\begin{array}{l}60 \\
60 \cdot 75 \\
0 \cdot 009\end{array}$ & $\begin{array}{l}23 \\
23 \cdot 50 \\
0 \cdot 005\end{array}$ & $\begin{array}{l}\text { I3 } \\
13.00 \\
0.000\end{array}$ & $\begin{array}{l}53 \\
55 \cdot 25 \\
0 \cdot 122\end{array}$ \\
\hline$-64 \cdot 88 \mathrm{~g}$ & $-292 \cdot 889$ & $-82 \cdot 000$ & $-44^{\cdot 000}$ & -104.444 \\
\hline $8 I \cdot 778$ & $432 \cdot 000$ & I $88 \cdot 000$ & $104 \cdot 000$ & $39^{2} \cdot 889$ \\
\hline
\end{tabular}

$$
\begin{array}{cc}
-588 \cdot 222 \\
\text { I } 98 \cdot 667 \\
(-588 \cdot 222)^{2} \div \text { I } 198 \cdot 667=288 \cdot 658
\end{array}
$$

Estimating intensity $(p=0.0386)$ :

$$
\begin{aligned}
& \sum_{\frac{m}{m}}^{a} \frac{d m}{d p} \\
& \left.n \sum_{\frac{1}{m}} \frac{d m}{d p}\right)^{2} \\
& \chi^{2} .
\end{aligned}
$$

\section{Total score}

\begin{tabular}{|c|c|c|c|}
\hline$-22 \cdot 688$ & $-31 \cdot 019$ & $+31 \cdot 954$ & $+26 \cdot 850$ \\
\hline 1183.702 & $6253 \cdot 034$ & $1266 \cdot 502$ & $700 \cdot 618$ \\
\hline 0.435 & 0.154 & 0.806 & $1 \cdot 029$ \\
\hline - & - & $\cdot \quad \cdot$ & +0.410 \\
\hline . & \multirow{2}{*}{\multicolumn{3}{|c|}{$0 \cdot 0386+\left(0 \cdot 4^{10} \div 9625 \cdot 680\right)=0.038643$}} \\
\hline$\cdot$ & & & \\
\hline $0.435+$ & $\cdot \dot{1}_{54}+\dot{0} \cdot 0$ & $1 \div \sqrt{9625 \cdot 6}$ & $\begin{array}{l}80=0.010192 \\
06=2.523\end{array}$ \\
\hline
\end{tabular}

Total information

Estimate of $p$

Standard error of estimate .

Heterogeneity $\chi^{2}$

Note. $-m$ is the expectation (in terms of $p$ ), and $a$ is the observed number, in each of the phenotypic classes of progeny. $\quad \Sigma$ indicates summation over these classes. $n=\Sigma a$.

Acknowledgements.-I am indebted to Professor R. A. Fisher, Sc.D., F.R.S., for guidance over the methods of analysis of the data and for permission to abstract the data up to the end of 1946 from the records at the Department of Genetics, Cambridge University. These data are given in table I. I am also deeply grateful to Dr D. S. Falconer and Miss M. E. Wright for helpful criticism and advice.

\section{SUMMARY}

I. Data are given which indicate close linkage between the agouti locus in the house mouse and the locus of Wright's mutant "undulated." Undulated therefore belongs to Linkage Group V. Its position with respect to pallid, wellhaarig, kreisler and hydrocephalus-I is not known.

2. The data are abstracted from the records at the Department of Genetics, Cambridge University; they are unselected, except that to 
ensure correct classification no mouse is included which died before the age of fourteen days or which was also classified as fused ; albinos, being unclassifiable for agouti, are also excluded. The data are chiefly of the intercross type (coupling and repulsion) but some are of the backcross type.

3. The results indicate good Mendelian segregation of undulated and of the agouti alleles involved. There is a highly significant interaction between them, which leads (by Fisher's scoring method) to an estimated recombination fraction $p=3.86$ per cent. with fiducial limits (for a 5 per cent. significance level) $p=2 \cdot 12$ per cent. and $p=6 \cdot 4^{2}$ per cent.

\section{REFERENCES}

CLARK, F. H. 1936.

P.N.A.S. 22, $474-47^{8}$.

DUNN, L. C., GRÜNEBERG, H., and SNELL, G. D. 1940.

7. Hered. 3I, 505-506.

FISHER, R. A. 1946.

Amer. Nat. 8 o, 568-578.

HERTWIG, P. 1942.

Z.I.A.V. $80,220-246$.

ROBERTS, E., and QUISENBERRY, J. H. 1935 .

Amer. Nat. 6g, 181-183.

STEVENS, W. L. 1942.

7. Genet. $43,301-307$.

WRIGHT, M. E. 1947 .

Heredity $1,137^{-1} 4^{1}$. 